\title{
Design of Urban Intelligent Drainage Control System
}

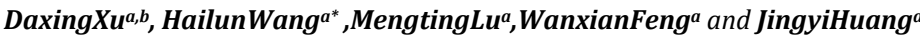 \\ ${ }^{a}$ College of Electrical and Information Engineering, Quzhou University, \\ Jiuhua Road, Quzhou, People's Republic of China \\ ${ }^{b}$ Department of Automation,Zhejiang University of Technology, \\ Liuhe Road, Hangzhou,People's Republic of China \\ *Corresponding Author: daxingxu@163.com
}

This is an open access article distributed under the Creative Commons Attribution License, which permits unrestricted use, distribution, and reproduction in any medium, provided the original work is properly cited

\section{ARTICLE DETAILS}

\section{Article History:}

Received 02 october 2017

Accepted 06 october 2017

Available online 11 october 2017

Keywords:

Waterlogging; pumping station; hierarchical control; monitoring system; intelligent drainage.

\section{ABSTRACT}

With the rapid process of urbanization, the major cities have suffered varying degrees of waterlogging because of urban heat island effect and the big probability of rainfall weather. Drainage pumping station, as the main facility in the construction of municipal administration and management engineering, undertakes the vital tasks of drainage and waterlogging-proofing. Along with the fast development of our country national economy, there is a higher demand in the construction and management. To promote the drainage pumping station turns into the unmanned supervision mode, this paper designs an intelligence drainage control system to reach the purpose our members will reduce and the ability of management will improve.

\section{Introduction}

Waterlogging not only causes traffic jam, but also lends to the heavy loss of properties. It has troubled the steady development of the city and is one of the major disasters factors,see [1, 2, 3]. Urban sewerage system is engineer system for eliminating rainwater and sewage, the important component of public facilities and the significance part of pollution and waterlogging control. Pumping station, a component part of sewerage system, uses high power pumps to drainage, irrigate, fill water to air transportation and municipal administration, etc, see $[4,5,6]$.

Drainage pumping station system consists of machines, electrical equipment and hydraulic engineering. It main control object is high power pumping unit. According to statistics, small pumping station that total installed capacity was below $1000 \mathrm{kw}$ adopted all-day manual operation mode in 1980s, such as manual recording pumping station operation data, manual control grille and controlling gate or pumping station running and stop. The automatic level in our country is low,see $[7,8]$. With the development of computer and control technology, see [9]. Drainage control system had experienced two major phases, computer-assisted and decentralized control. Computer decentralized control system can acquire and analyze the information of water level and sewage flow, and handle it with controlling pump work. It can provide the timely data, and monitor the pumping station. Urban drainage pumping station widely uses localebased computer decentralized control manner, but it blocks the exchange of information from different regions of pumping station. Due to the advanced computer networks technological on transmission and longrange control, distributed control system based on network, having the high stability, reliability and expandability, has been developing quickly in recent years,see [10]. Distributed control system has been used in all fields since the first distributed control system, TDCS-2000, appeared in Honeywell. Depending on convenient configuration software, control algorithm and open network capability, it gradually becomes the mainstream of automated control and the developing direction of drainage control system, see $[11,12]$

To make sure urban drainage system coordinated optimization control, intelligent drainage emerges at a historic moment. This paper designs an intelligent drainage control system based on hierarchical control structure, taking advantages of pipe network, river and modern network control technology to build the upper network on coordinating control system. PLC (Programmable Logic Controller) transmits the parameters of water level and sewage flow to central server by the better transmission efficiency of Ethernet, and then based on the model of urban distributed drainage system, it adopts optimization technique to acquire the best way to water dispatch in urban drainage system including the overall pumping station by the global coordination and optimization. Finally through the Web, orders are issued that pumping station coordinates the water flow to pumping station. Meanwhile, to solve the blind zone problem during network interruption, congestion and data loss, we build intelligent control system based on reliable PLC as the lower control center to ensure drainage system works normally all the time.

\section{Systemfunctionoverview}

As for a single city pumping station, it is mainly used for flood control, drainage and sewage discharge in nearby counties and cities. Pumping station facilities play a key role in urban flood control, drainage and water diversion and irrigation. With the rapid development of China's economic construction, higher requirements have been put forward for water conservancy facilities and water environment. Urban flood control and drainage, urban water environment, deep water wells and drainage facilities are faced with the use of modern information technology to further enhance the facilities. The tide, drainage, drainage, water diversion pumping station automation monitoring and centralized management, real-time acquisition of a variety of water regime data is the foundation of information technology.

This paper aims to design a through shared Ethernet communication and Internet connection control, hierarchical control structure of intelligent city drainage system network coordination scheduling framework based on optimal scheduling of network coordination to achieve multi loop controller drainage system. The control system for balance and pump inlet volume, has important significance to meet the daily safety and enhance the dual requirements of city drainage waterlogging drainage capacity.

\section{Systemfunctionoverview}

\subsection{System object}

By orderly controlling of the pump station,pump station's running equipment, electricity, water level and other real-time information are 
collected to the control room for remotely monitoring;and they can be browsed on the screens of the computers within LAN,making administrative staffs to operate pumping station appositely.

Of course, in order to ensure that pumping stations can also operate normally even losing control in the disaster weather,local operations must be performed at the pump stations.Each pump station is equipped with a local touch screen operating system,each pump working state and operation data can also be monitored in real time on the interface.

Monitored parameters:

Power parameters: such as the factor of power equipment voltage, current,power.

Drainage pump parameters:the state of running and overload,on and off of pump,etc.

Water quantity information:water level, flow rate, accumulated flow rate, etc.

Entrance guard system:it is used to strengthen automatic safety control and control of pumping station.

Video frequency (V.F.):camera equipment monitors water level of pumping station and the safeties and theft prevention of facilities.

\subsection{Design of system hardware}

Local pumping stations are comprised of control systems with lower PLC as the core,Not only can the central server realize the information sharing and regional coordination and optimization control, but also the control blind area caused by the industrial computer fault is compensated by the local control system.The following describes the local hardware design first:

Local control system hardware circuit composition is shown in Figure 1,it is mainly comprised by all kinds of sensors, transmitters, PLC, frequency converter, data boards and relays and other equipment.The software architecture of the control system is mainly composed of two parts: data acquisition and processing and local intelligent optimization control.

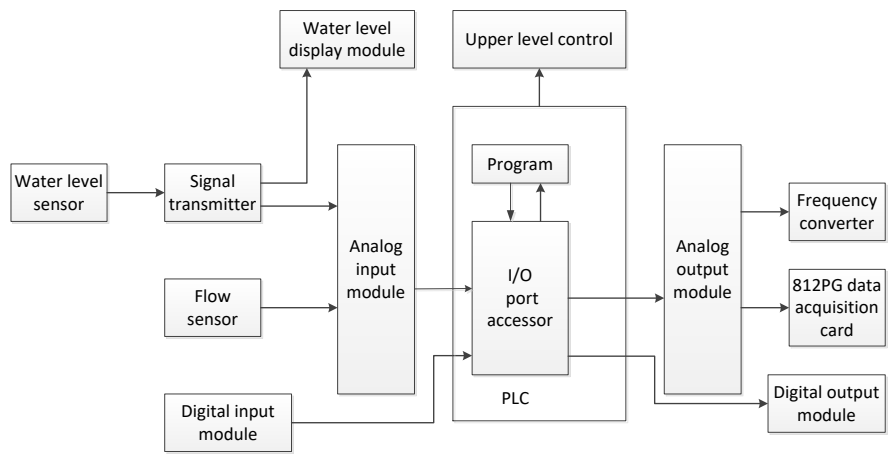

Fig. 1 Block diagram of local control system hardware circuit composition

\section{A) The Link of Data Collection and Processing}

The PLC comes with four AD analog sampling channels loop scan peripheral sensors of control system,water levels collected by transmitters,flow signal,output control quantity of industrial personal computers.Taking water level signal acquisition as an example to explain,the water levels in the intake tanks are converted into standard 4$20 \mathrm{~mA}$ electrical signals by SIEMENS ultrasonic sensors, they are connected to the analog input module of PLC through double shield line,then the data acquisition program segment is wrote to achieve electrical signal acquisition, conversion, preservation and display.200, W20, W102, W51 and 211 of them are internal registers of the PLC,the execute time of transfer instruction (MOV) is 0.3 us,the execute time of upper and lower limit control instruction(LMT) is 27.23 us.

\section{B) The Link of Local Intelligent Optimization Control}

The local intelligent optimization control unit consists of two parts: the intelligent control power decision and the PLC subsection Frequency Conversion Optimization control.Its working flow chart is shown in Figure 2 , when the IPC is working correctly,control system carries out coordinated control of network optimization;the lower PLC achieves periodical cyclic retrieval.When PLC detects an industrial computer abnormal,sub link PLC access to system control by the intelligent decision for subsection frequency conversion control, it sends out industria computer fault alarm and continues cycle detection at the same time.

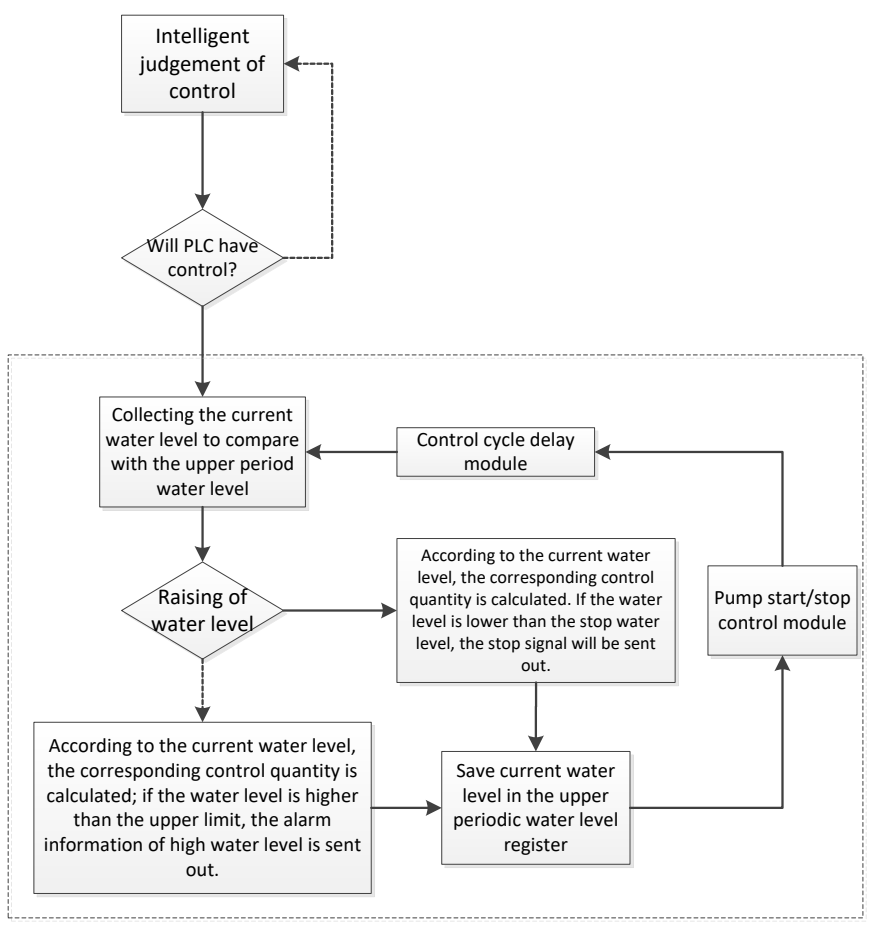

Fig.2.Working principle diagram of local intelligent optimization control

\subsection{Design of system software}

This project constructed a city intelligent drainage control system based on hierarchical control structure, it takes lower local control as the hardware foundation,the upper IPC as the core of the software.The upper network control system of urban drainage is shown in Figure 3,the Ethernet is chosen as the shared network platform for high transmission efficiency,the field IPC of pumping station are connected directly through RS-232 to obtain sumps of the pumping stations water levels, sewage flows and other process parameters collected by PLC,then transfer the information to the central server and save them in database.Then the central server achieves the multi-target control of the drainage system through the regional coordination and optimization decision knowledge base.

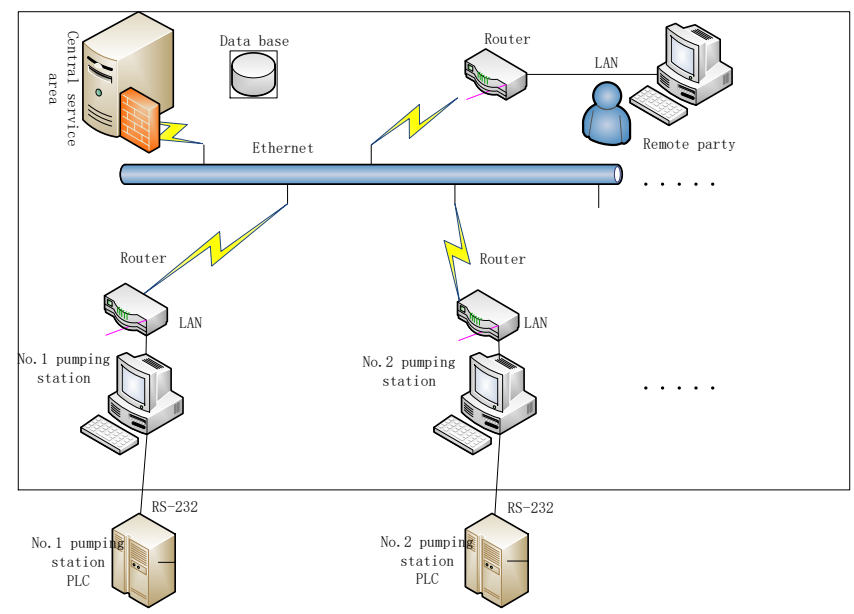

Fig. 3 Architecture diagram of upper layer network control system with IPC as core

Finally,comprehensive dispatching urban drainage system of pumping station to achieve global coordination optimization to make sure the drainage system runs continuously for long periods of time.As a result, hierarchical urban drainage network control system architecture has been researched in this paper

Hierarchy system is composed of the network control system based on the 
upper IPC and local control system with lower PLC as the core which are independent and connective to each other.Not only can the central server realize the information sharing and regional coordination and optimization control, but also the control blind area caused by the industrial computer fault is compensated by the local control system. The specific system architecture diagram is shown in figure 4,The A part surrounded by the dotted lines are several network coordinated feedback control loops,they consist of several regional pumping stations' local controllers and central coordination controller;the B part surrounded by the solid lines are several network supervisory control loops,comprise many remote monitors and local controllers.Central coordination controllers,network supervision controllers,local controllers and regional pumping stations distributed in elsewhere,connected by the Internet network,regional pumping stations can response to remote feedback, coordinate control instructions and regulatory control commands.Pumping station system is mainly composed of sensors, pump groups and controlled objects.For fixing each local controller class, central coordination controllers can identify each local controller after the service application is started,and send the control signals automatically, receive the pump stations the data. Peer to peer C/S structure that is adopted in this project is achieved by Microsoft.NET's distributed software architecture,each controller application in the network can play the role of server and client at the same time.

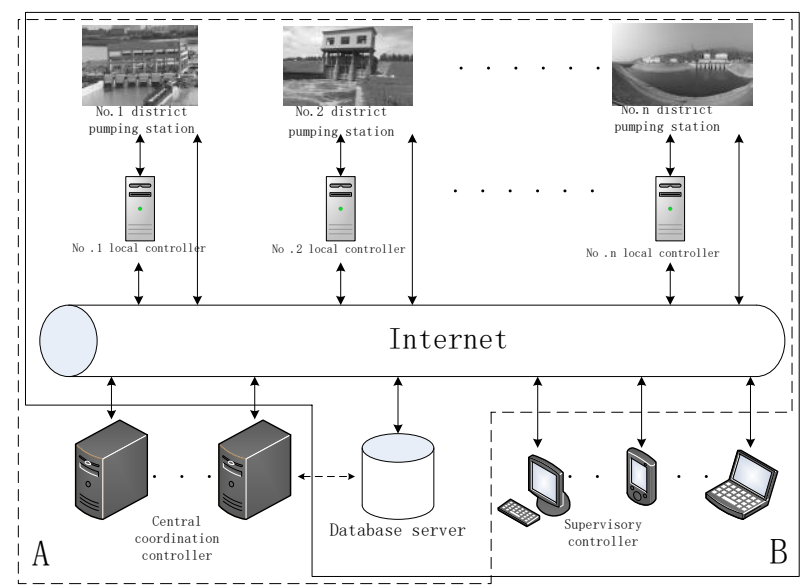

Fig. 4 City intelligent drainage control system based on hierarchical control structure

Large on-site high performance data acquisition and monitoring of pumping stations can be achieved by configuration software,Real-time water regime (The data of hydrological water quality monitoring system of hydrology terminus is main foundation) 、 rain condition (The rainfall observation station nearby is loaded with rainfall runoff model to calculate) 、 project (The information of gate, pump, motor and power supplied by Automatic monitoring system for sluice and pumping station ) are main basis for decision making,at the same time,integrating other system information ( $S u c h$ as drainage information system,the geoinformation system of water resources census, etc.) and combining the latest or forecasted weather information,under the action of the expert system, the simulation results under different operation control are generated to determine the best flood prevention and diversion scheme and displayed in an intuitive and WEB manner.

As the pumping station monitoring equipment has some, so under the full use of existing equipment,control transformation achieve controlling water pumps and the saving purpose.

\section{Conclusion}

In this paper, a set of networking technology, cloud computing and control in one, form a comprehensive management and control platform, the multiple management departments in one set, planning to change the way of thinking, to avoid fragmentation caused by waste, promote the city planning to start from the source, the results of data analysis for water diversion and drainage, make the whole system work and standardization.
There are many advantages: 1) to save the operating costs of drainage enterprises; 2) easier to manage; 3) to reduce the workload of workers; 4) to enhance urban drainage effect.

\section{Acknowledgments}

This work was supported by Foundation ofQuzhou science and Technology Bureau (No. 2016Y007).

\section{References}

[1] Notice of the General Office of the State Council on the Construction of Urban Drainage and Waterlogging Facilitieshttp://www.scio.gov.cn/32344/32345/32347/33553/xgzc335 59/Document/1451035/1451035.htm

[2] Notice of the Ministry of Urban and Rural Construction on the Outline for the Compilation of Outline of Urban Drainage (Rainwater) Waterlogging.

http://www.mohurd.gov.cn/zcfg/jsbwj 0/jsbwjcsjs/201306/t20130627 214142.html

[3] Pang, K. W., Shang, Y. B, Yu, Y. P., \&Liang. B. Y. (2006). Design forControlSystem ofHigh PowerMotorin Urban Sewage Pump Station. China water supply and drainage, 22(4): 52-55.

[4] Xiao, H., Zhang, X. H., Li, H. M., \&Ou, C. Y.(2008). Design and Implementation of a Remote Control System.Journal of Shanghai University (Natural Science Edition) ,14(3): 239-243.

[5] Kim, W. J., Kun J. \& A. (2016).Real-time operating environment for networked controlSystems.IEEE Transactions on Automation Science and Engineering, 3(3), 287-296.

[6] Hsu, M. H. \& Chen, S. H. (2012).Inundation simulation for urban drainage basin with storm sewer system. Journal of Hydrology, 2000 (234): 21-37

[7] Thorndahl, S. \&Willems, P.(2008).Probabilistic modelling of overflow, surcharge, and flooding in urban drainage using the first order Reliability method and Parameterization of local rain series.Water Research, 42(1):455-466.

[8] US EPA.(1994). Combined SewerOverflow(CSO) control Policy, Federal Register, Tuesday, April 19, 59(75).

[9] Ermolin, Y. A.(2009). Mathematical modelling for optimized control of Moscow's sewer network [J]. Applied Mathematical Modelling, July, 23(7):543-556.

[10] Maeda, M., Mizushima, H. \& Ito, K. (2015).Development of the realtime control (RTC) system for Tokyo sewage system [J]. Water Science and Technology, 51(2):213-220.

\section{About the Authors}

DaxingXu received the bachelor degrees in mathematics from Henan University, Kaifeng, China, and the master degree in control theory and control engineering from Hangzhou Dianzi University, Hangzhou, China, in 2011, and 2014, respectively. He is currently an assistant with College of Electrical and Information Engineering, Quzhou University, Quzhou, China.His current research interests include information fusion technology based on sensor networks, Pump station drainage control.

Hailun Wang received the bachelor degrees in control engineering from Changchun University of Technology, Changchun, China, and the control engineering from Zhejiang University of Technology, Hangzhou, China, in 2002, and 2010, respectively. She is an associate Professorwith College of Electrical and Information Engineering, Quzhou University, Quzhou, China.

Mengting Lu, WanxianFeng and Jingyi Huang areUndergraduates with the College of Electrical and Information Engineering, Quzhou University, Quzhou, China. 